\title{
O Espírito de 32
}

\author{
Pedro Brasil Bandecchi \\ Secretário Geral da Associação dos \\ Antigos Alunos da Faculdade de Direito \\ da Universidade de São Paulo
}

\section{Bibliografia da Revolução}

A Bibliografia da Revolução Constitucionalista de 1932 é vasta. Terminado o movimento, não tardaram a aparecer as primeiras obras e inúmeros artigos, que logo se multiplicariam.

Áureo de Almeida Camargo publicou, no no 91 da Revista de História, no $40^{\circ}$ aniversário da Revolução Paulista, interessante informe, sob o título Roteiro de 32 , onde relaciona com boa técnica e melhor cuidado, livros, folhetos, jornais, revistas, composições musicais, poesias e gravações, apresentando claros resumos dos primeiros, com o objetivo de facilitar o trabalho do pesquisador.

Este Roteiro se estende por 58 páginas, o que mostra a importância e riqueza de bibliografia em tela.

Bibliografia rica em depoimentos, em crônicas e mesmo em obras históricas. É certo que, muitas vezes, é difícil saber-se onde acaba a crônica e começa a história, como assinala o mestre Capistrano de Abreu em seu estudo sobre Varnhagen. Trabalhos escritos ainda no calor das paixões, muitos deles são libelos veementes. Outros procuram estudar o movimento em si. Há os que decrescem a luta em uma das frentes de batalha e ainda os que falam do trabalho na retaguarda para manter as frentes, tendo por objetivo amenizar o drama e o sacrifício do embate. $\mathrm{E}$, ainda, os que estudam mais aprofundadamente as causas da revolução e sua finalidade. Uns mais e outros menos são fontes onde o historiador irá colher o material necessário para a análise da epopéia paulista, epopéia que revelou, mais uma vez, a alma indômita, tenaz, valente, construtiva e democrática de São Paulo.

Nos livros de história pátria há ainda, com raras exceções, uma certa parcimônia no espaço reservado à Revolução de 32 . Isto quando lhe dedicam algumas linhas. Entre as exceções encontram-se a História do Brasil, de Pedro Calmon, que dela se ocupa demoradamente, 
- mesmo acontecendo com a História do Exército Brasileiro, de Antonio de Sousa Júnior e outros, edição do Estado Maior do Exército, 1972. Em o Novo Dicionário de História do Brasil e no de Estudos Sociais, de Brasil Bandecchi, Leonardo Arroyo, Ubiratan Rosa e outros (Melhoramentos) os verbetes sobre a revolução além de longos são completados por outros afins com informações e biografias.

Porém, mesmo com a enorme bibliografia referida (gostaria sinceramente de estar enganado), a Revolução de 1932, é mais sentida do que conhecida. E sentida quase que exclusivamente pelos paulistas e por não paulistas aqui radicados, que a viveram. $\mathrm{E}$, assim mesmo, em Piratininga há os que a tratam com indiferença e até com desdém.

Não culpo os indiferentes pelo que acontece. Na verdade os brasileiros, mesmo com o rádio e a televisão, mal se conhecem. Nós não nos lemos e o que vemos, na quase maioria absoluta das vezes, mostra a imagem mas não revela a alma.

Há alguns anos, o então promotor público e hoje ilustre magistrado em Brasília, Dr. Dario Viotti, chamava minha atenção para o fato de que em São Paulo ninguém lia jornais e revistas de Minas e vice-versa. E desse desconhecimento, dizia-me, é que tem surgido muitos equívocos. Os paulistas mal sabiam (ou sabiam mal) a oposição que Arthur Bernardes movia ao governo de Minas e o receio que os seus adversários políticos tinham que ele voltasse ao poder com a vitória constitucionalista. Foi esta uma das causas de muitos políticos mineiros não terem acompanhado São Paulo em 32 e até se colocarem em posição contrária.

Há, também, os que informam mal e erradamente. No livro Estudos de Problemas Brasileiros, escrito sob a orientação do Padre Leme Lopes S.J., e publicado pela Biblioteca do Exército e Renes/Editores, Rio de Janeiro, 1971, lê-se à página 28 (Unidade 1, Introdução Doutrinária, de autoria do Prof. Armando de Oliveira Marinho).

"A segunda Constituição Republicana, promulgada em 16 de julho de 1934, traz no seu bojo uma conjugação do liberalismo, consagrado na sua antecessora, com as idéias da social democracia. No fundo lhe serviu de inspiração a Constituição alemã de Weimar, de 1919. Ao ser elaborada, predominou a intenção de erigir um regime democrático com a preservação da unidade nacional, ameaçada pela Revolução paulista de 1932."

A Revolução de 1932 não ameaçou a unidade nacional, salvo se defender o império da lei seja um ideal exclusivo de São Paulo.

Mas, felizmente, não é.

$\hat{E}$, isto sim, um dever indeclinável que pertence a todo o homem que ama a liberdade e a ordem democrática constitucional.

A história de São Paulo, entretanto, prova que a Revolução de 1932 tinha um objetivo bem diferente daquele que muitos lhes queriam 
inquinar e raízes muito mais profundas que só podem ser vistas por aqueles que não ficam na superfície dos fatos.

São Paulo exigia a Reconstitucionalização do país. São Paulo estava, como sempre esteve, ao lado da lei.

\section{O Liberalismo em São Paulo}

As idéias liberais começaram a penetrar no Brasil no último quartel do século XVIII e são o fermento político da Independência. Elas inspiraram os inconfidentes de Minas Gerais e os revolucionários pernambucanos de 1817. Sufocadas a partir desse ano aflorariam com redobrada força no movimento que culminaria no 7 de Setembro na Colina do Ipiranga, e tomaria corpo com a fundação dos cursos jurídicos no Brasil, principalmente em São Paulo, onde a instalação da Academia, em março de 1828, marcaria página brilhante dos fastos nacionais.

Miguel Reale escreve que as idéias liberais penetraram na Faculdade do Largo São Francisco sob o influxo de Líbero Badaró e Júlio Frank.

Badaró, médico italiano, redator do Observador Constitucional, assassinado a mando do absolutismo dominante, foi um marco indelével na pregação do liberalismo. Júlio Frank, fundador da Burschenschaft (Bucha), trazia da vclha Alemanha o espírito de luta contra o absolutismo reinante na Europa.

São Paulo com estrondo, como fez, aliás, todo o mundo livre, festejou a queda de Carlos X, da França, e à frente das manifestações estavam os jovens estudantes da recém-instalada Faculdade do Largo São Francisco.

Liberais e do melhor quilate eram os paulistas Padre Feijó, Antonio Carlos, Paula Sousa, Tobias de Aguiar, entre muitos. Liberal era o primeiro professor da Academia, José Maria de Avelar Brotero, fugido de Portugal por ter-se metido em encrencas políticas contra o regime dominante.

E liberalismo, em política, nada mais é do que o constitucionalismo expresso, num documento político fundamental, onde constem a divisão e harmonia dos poderes e o capítulo dos direitos e garantias individuais.

Este princípio encontra-se consagrado no artigo 16 da Declaração dos Direitos do Homem, de 26 de agosto de 1789, votado pela Assembléia Nacional Francesa, no ardor da grande revolução:

"Toda sociedade, na qual a garantia dos direitos do homem não é assegurada nem a separação dos poderes determinada, não tem Constituição." 
Vê-se, pois ai, que o constitucionalismo, em São Paulo, dentro do melhor liberalismo, tem profundas e boas raízes.

E quando D. Pedro I enveredou pelo atalho do absolutismo, São Paulo marcou sua presença na campanha que o levou a abdicar na pessoa de seu filho, Pedro de Alcântara, no dia 7 de abril de 1831.

$\mathrm{E}$ a significação do ato do Imperador foi tão largo, que logo no Rio de Janeiro e no Brasil, tornou-se popular a seguinte quadra:

"No dia 7 relembro

altas glórias do Brasil,

a Independência em setembro

e a liberdade em abril."

\section{Revolução Liberal de $\mathbf{1 8 4 2}$}

Com a queda de D. Pedro, instalou-se, no Brasil, o período regencial, também conhecido como "experiência republicana." Nesse período a Câmara dos Deputados, dominada pelos liberais, realizou algumas reformas e editou o Ato Adicional de 1834, com colorido descentralizador, desfigurando de alguma forma o unitarismo da Carta Magna.

Em 1840, uma revolução branca declarou D. Pedro II maior, obra dos liberais, entre eles Antonio Carlos, Martim Francisco, José Martiniano de Alencar. Em 1841 cairam os liberais e subiram os conservadores que iniciaram a anulação das conquistas avançadas da Regência, num movimento chamado Regresso, ou seja, a volta ao sistema vigente no primeiro reinado. Duas leis caracterizam o regressismo, ambas de 1841: a que criou o Conselho de Estado (23 de novembro), que fora extinto pelo Ato Adicional, e a que reformulou o Código de Processo Criminal (3 de dezembro).

Os liberais vencidos no Parlamento, saíram a campo, combatendo essas leis e os conservadores.

Otávio Tarquínio de Sousa (Diogo Antonio Feijó, Rio de Janeiro, 1942, p. 293) escreve:

"Na Corte, visando de preferência as províncias, um clube dirigido por Limpo de Abreu e Teófilo Otoni pôs-se a trabalhar por todos os meios, agitando a opinião pública e procurando intimidar o governo com a ameaça de um desfecho violento."

Que clube seria esse que o consagrado historiador nomeia tão vagamente e lhe empresta atividade tão grande?

O livro de Tarquínio de Sousa é de 1942 e o de Aluísio de Almeida, sobre a Revolução Liberal de 1842 , é de 1944 , o que me leva a crer que o biógrafo de Feijó não conhecia a Sociedade dos Patriarcas Invisiveis, ou se conhecia, não dispunha de maiores elementos sobre ela, o que o fez tratá-la com certo laconismo, sem mesmo se referir a Alencar. 
Afonso de Taunay, na sua História da Cidade de São Paulo (São Paulo, 1977, vol. VI, p. 43 e segs.) trata da Sociedade baseado exclusivamente em Aluísio de Almeida.

Aluísio fala com segurança da Sociedade dos Patriarcas Invisiveis, cuja finalidade era defender a Independência do Brasil, a Constituição e opor-se às arbitrariedades do governo. E se propunha a ajudar o Corpo Legislativo por palavras escritas, censurando pela mesma maneira os atos inconstitucionais do governo e seus empregados, opondo-lhe resistência e promovendo a união entre todos os brasileiros, explanando quanto possível os obstáculos correntes ( $A$ Revolução Liberal de 1842, São Paulo, 1944, p. 34). Dentro desta finalidade Defesa da Constituição e Independência do Brasil - que a Sociedade dos Patriarcas Invisíveis, da qual faziam parte Rafael Tobias de Aguiar, Âlvares Machado, Hercules Florence, Joẫo Floriano de Toledo, Amara] Gurgel, Padre Valério de Alvarenga, Major Francisco de Castro Canto e Melo (irmão da Marquesa de Santos), Gabriel Rodrigues dos Santos, Feijó, Padre Manuel José França e outros, e a Província de São Paulo se ergueram no famoso movimento de 1842, juntamente com Minas Gerais, esta sob o comando de Teófilo Otoni.

Mais uma vez, portanto, a vocação constitucionalista de São Paulo se opõe ao arbítrio.

$E$ durante toda a monarquia duas idéias orientam o pensamento político paulista, cujo fulcro é a Faculdade de Direito: a abolição e a república.

As sociedades abolicionistas e republicanas (secretas ou não) têm seus jornais, suas sedes e realizam reuniões em recintos fechados ou na praça pública, lutando pela liberdade de uma raça escravizada ou propugnando por um regime "Onde todo o poder emana do povo e em seu nome é exercido."

Os três primeiros presidentes civis da República eram paulistas e convictamente democratas. A Faculdade de Direito de São Paulo, disse alguém com muito realismo, deu alguns presidentes da República e nenhum ditador.

Isto posto, fica evidenciado, que a Revolução Constitucionalista de 1932 não foi um episódio isolado na História de São Paulo, porém, mais uma vez, a presença altiva de São Paulo na História do Brasil.

\section{Revolução de 30}

Júlio Prestes, candidato do Dr. Washington Luís, saíra vitorioso nas eleições de $1^{\circ}$ de março de 1930 e com isto não se conformaram os partidários de Getúlio Vargas, que alegavam cerceamento na campanha e fraude eleitoral praticada pelo governo federal.

Getúlio era presidente do Rio Grande do Sul. 
Neste passo prefiro dar a palavra a um ilustre escritor e historiador pernambucano, Barbosa Lima Sobrinho, que expõe:

"É claro que a exaltação seria tanto maior quanto mais vivo fosse o sentimento em causa. No Rio Grande do Sul, por exemplo, a paixão regionalista, despertada pela campanha, tornava praticamente impossível a propaganda do candidato adverso ao presidente daquele Estado. Ao contrário, em São Paulo, que não acompanhou os acontecimentos com preocupações regionalistas, a liberdade foi ampla para os comícios políticos e para a ação da imprensa partidária. Esse foi, aliás, o ambiente geral da campanha. O jornalismo disse tudo o que quis, relativamente aos próceres da campanha. Não faltaram acusações contra o Sr. Washington Luís, sem que se observasse nenhum desforço. As caravanas liberais (o Sr. Getúlio Vargas era candidato da Aliança Liberal) percorreram o país, acendendo por toda a parte o facho rubro da revolução. $O$ estado de sítio que se tornara normal no quatriênio do Sr. Arthur Bernardes, desapareceu de todo; a censura à imprensa mergulhou também entre os usos esquecidos."

Assim, com ampla liberdade, chegou-se à eleição de $1^{\circ}$ de março, saindo vitorioso o Sr. Júlio Prestes, como foi dito.

Voltemos, agora, a Barbosa Lima Sobrinho:

"Alegavam-se fraudes, violências, vícios de toda ordem, mas a impressão geral era aquela, que Raul Soares externava em 1922: em geral os vícios das atas se reproduzem normalmente em São Paulo, Minas, Rio Grande, pois as eleições, por toda a parte, no Brasil, são em geral feitas por homens da mesma mentalidade e da mesma cultura. "Sob certo aspecto, em 1930, poder-se-ia mais facilmente arguir de defeito na eleição, do Rio Grande do Sul do que em qualquer outro estado."

\section{E esclarece:}

"De mais, não haveria, sob todos esses aspectos, maior indício de irregularidade que o pleito do Rio Grande do Sul, com o resultado fabuloso que apresentou; 298.627 votos para o Sr. Getúlio Vargas e 982 para o Sr. Prestes. Por maior simpatia e melhores sentimentos que inspirem uma campanha, não é possível esperar unanimidade, senão com auxílio do processo de coação. Normalmente, num pleito livre que se suceda a uma campanha igualmente livre, não seria possível aquele resultado."

Vencidos nas urnas apelaram para as armas. E num movimento que durou apenas 21 dias (de 3 a 24 de outubro de 1930), sob o comando geral do Sr. Getúlio Vargas, foi deposto o Dr. Washington Luís Pereira de Souza e anulada a vontade expressa nas urnas.

Em São Paulo, a Aliança Liberal tinha o apoio do Partido Democrático. Ou melhor, o Partido Democrático adotara a candidatura de Getúlio Vargas, em sessão plenária do seu Quinto Congresso (extra- 
ordinário), realizada no dia 31 de agosto de 1929, no Palácio Taçaindaba, na Cidade de São Paulo.

A Revolução de 30 não trazia no seu bojo uma unidade de pensamento em torno de um programa.

A História do Exército Brasileiro é a obra que, na sua natureza, traz o relato mais completo da Revolução Constitucionalista. E comparando a proclamação da República com a Revolução de 30 , sentencia:

"A República contava, em sua implantação, com uma elite de bacharéis e militares idealistas, razoável uniformidade de propósitos. Todavia, a Revolução de 1930, um amontoado de tendências divergentes, não possuindo, inicialmente, para guiar-lhe a ação reconstrutora, princípios orientadores, postulados ideológicos definidos e propagados que sintetizassem as aspirações dos que a tinham preconizado." (Vol. III, 934).

Tudo indica que o grande objetivo era acabar com a oligarquia paulista e reforçar a oligarquia gaúcha, muito mais enraizada e forte do que a primeira.

\section{Paulista e Civil}

No recém-fundado Clube 3 de Outubro se aninhavam os revolucionários de 30 e os tenentes que vieram no seio ou na esteira da revolução.

Os velhos membros do Partido Republicano Paulista (PRP), que os tenentes chamavam de carcomidos, sofreram vexames e perseguições, mas saíram ilesos na sua dignidade. Em breve se uniriam aos seus inimigos de ontem e amigos de anteontem: os democráticos.

Os chefes da Revolução de 30 não respeitaram, em São Paulo, sequer os aliados. Não entregaram São Paulo a um paulista, mas nomearam o Tenente João Alberto, pernambucano, primeiro, Delegado Militar da Revolução e, depois, Interventor Federal do Estado bandeirante.

Aqui começaram os desentendimentos entre os vencedores e a amargura dos vencidos.

$\mathrm{E}$ desiludidos e amargurados se unem e todos querem para governar São Paulo: um Paulista e Civil.

Fechadas as câmaras, ou melhor, extinto o poder legislativo, e a Constituição de 1891 modificada em alguns passos para atender às circunstâncias, a situação tornou-se intolerável. Os carcomidos recobraram suas forças e passaram a reclamar a convocação de uma Assembléia Constituinte.

Em março de 1932, Getúlio Vargas discursando aos outubristas, insistia "na necessidade de proceder antes da Constitucionalização à 
capina do terreno, das ervas daninhas que o esterilizam." $\mathrm{E}$ sobre aqueles que desejavam apressar a volta do regime constitucional, classificou-os, como carpideiras, saudosistas das delícias fáceis do poder ou incorrigiveis doutrinários alheios às realidade nacionais." (História do Exército Brasileiro, III, 934).

O candidato natural de São Paulo, terminada a revolução, era o Professor Francisco Morato, líder do Partido Democrático e cidadão de reconhecidas virtudes. Mas o chefe da revolução e chefe do governo provisório preferiu o líder tenentista.

Como era de se esperar, o Partido Democrático acabou rompendo com o Interventor João Alberto e logo depois com o próprio Getúlio Vargas.

Enfim, os tenentes de 1922, 1924 e 1930, eram pelo governo discricionário e julgavam prematura qualquer tentativa do retorno do país à ordem legal. O Clube 3 de Outubro tinha nos seus quadros o tenentismo e os intransigentes (e muitos oportunistas, quase sempre piores que os outros para mostrar serviço) de tal maneira que Getúlio preferiu ficar com os tenentes, que representavam a força a ficar com os desarmados, que aspiravam a lei.

Mesmo assim, Getúlio cedeu à campanha dos paulistas que reclamavam um paulista e civil para governá-los. Nomeou, então, o Ministro Laudo Ferreira de Camargo, que não se curvando às injunções tenentistas teve que largar o governo, sendo substituído pelo General Manuel Rabelo.

Tudo pela Constituição! E o lema paulista de uma campanha memorável, que tinha à frente estudantes das escolas superiores, principalmente os do Largo São Francisco, o Partido Republicano Paulista e o Partido Democrático.

Os ânimos se agitam e o brado reboa: Tudo pela Constituição !

Diante da onda que crescia, Getúlio Vargas nomeou para a interventoria paulista um antigo político e velho diplomata: o Embaixador Pedro de Toledo, ao qual quis impor um secretariado. Pedro de Toledo, no entanto, nomeou auxiliares de sua escolha e inteira confiança.

Criou-se o impasse.

A campanha constitucionalista ganhou a praça pública e o povo agora quer, reclama e exige uma Constituição.

$\mathrm{E}$ a participação do povo foi da maior importância não só na fase preparatória do movimento como, e principalmente, durante a luta. Foi um dos momentos históricos em que ele tomou parte e o sentiu realmente.

Numa dessas manifestações populares, ao cair da tarde de 23 de maio de 1932, na Praça da República, perto da Rua Barão de Itapetininga, dos prédios vizinhos os partidários da ditadura come- 
çaram a atirar contra os manifestantes, matando cinco populares: Mario Martins de Almeida, fazendeiro em Sertãozinho; nascido em São Manuel, São Paulo, em 1901; Euclides Bueno Miragaia, auxiliar de cartório em São Paulo, nascido em São José dos Campos, São Paulo, em 1911; Drausio Marcondes de Sousa, estudante, nascido na Cidade de São Paulo em 1917 e tinha 14 anos de idade quando morreu; Antonio Américo de Camargo Andrade, do Comércio, nascido em São Paulo, em 1901; e Orlando de Oliveira Alvarenga, escrevente juramentado, nascido em Muzambinho, Minas Gerais.

Com as iniciais dos nomes por que eram conhecidos os quatro primeiros, formou-se o MMDC (Martins, Miragaia, Drausio e Camargo) entidade das mais destacadas da Revolução de 32 . O nome de Orlando de Oliveira Alvarenga não apareceu, porque este veio a falecer em 12 de agosto, quando o MMDC já estava organizado. Mas fica aqui a justa homenagem e a gratidão de todos os constitucionalistas.

23 de maio foi o selo de sangue na página constitucionalista, que uniu todos os paulistas e filhos de outros Estados e até de outros países, no ideal supremo.

Os inimigos de São Paulo perceberam que essa união era firme e notaram o rumo dos acontecimentos. A 5 de julho, quatro dias antes do início da revolução, lançaram um boletim intitulado $\mathrm{ACa}$ morra de Cima. A camorra era, para eles, os chefes do movimento constitucionalista. Queriam, com esse boletim, dividir os paulistas como haviam feito em 30 , mas não conseguiram.

No dia 9 de julho estoura a revolução e no dia seguinte, Pedro de Toledo foi aclamado, no Pátio do Colégio, pelo povo e pelas forças armadas, governador de São Paulo, deixando de ser delegado do poder central para ser mandatário dos paulistas.

O Professor Waldemar Ferreira em conferência pronunciada, em 1957, na Faculdade de Direito (A Faculdade de Direito na Arrancada de 9 de julho de 1932) lembra que Bernardo Pereira de Vasconcelos, ao manifestar-se contrário à criação dos cursos jurídicos em Olinda e em São Paulo, assim se manifestou:

"Julgo que para maior liberdade dos mestres e alunos na explicação e desenvolvimento das doutrinas, convém que por enquanto se estabeleçam estas aulas no Rio de Janeiro. Do contrário, não me admiraria se soubesse que o Presidente da Província, onde estivesse o Curso Jurídico, tenha mandado em ferros, para as fortalezas destas Cortes, os professores e os estudantes - como republicanos e incendiários."

\section{Waldemar Ferreira comenta:}

"Temeu o parlamentar que os mestres e estudantes do Curso Jurídico de São Paulo viessem a ser republicanos e incendiários e fossem um dia mandados em ferros para as fortalezas do Rio de Janeiro; e a temência se converteu em realidade. Mestre e estudantes 
foram mandados em ferros para aquelas fortalezas e prisões em 1932; e daí para o exílio em Portugal.

Não tem sido realmente outro o fadário do Curso Jurídico de São Paulo. Seus mestres e estudantes, desde que os mestres foram os próprios estudantes, elevados às cátedras ao pé das quais se formaram, sempre entenderam que a missão histórica daquela casa não seria apenas a de dar ao país profissionais para os quadros da magistratura, do ministério público e da advocacia, mas acima de tudo a de preparar homens que pudessem enaltecê-lo nas letras, nas artes, na política e na administração pública, convertendo-se em sementeira de políticos e estadistas, como aconteceu."

$\mathrm{E}$ foi desta Faculdade que partiu o primeiro batalhão constitucionalista, formado na maior parte por estudantes, sob o comando de Romão Gomes.

Este é o espírito de São Paulo. Este é o espírito da Revolução Constitucionalista de 32 . 